\title{
The Leadership Skills and Organizational Climates in the Public Higher Educational Institution in Zamboanga del Sur, Philippines
}

\author{
Cleofe A. Baterna Jr., Renato L. Base, Ph.D. \\ a.J.H Cerilles State College, Mati, San Miguel, Zamboanga Del Sur, Philippines \\ cleofe. baterna @ jhcsc.edu.ph \\ b. USTP-CDO Campus, Cagayan De Oro City, Philippines \\ renato. base @ ustp.edu.ph
}

\begin{abstract}
Leaders define the blueprint of any organization. leadership is the single most important ingredient of an organization's success. It has the power to make the system attain excellence and achieve goals. This paper aimed to determine the level of the leadership skills of the administrator in the Public Higher Educational Institution (PHEI) in Zamboanga del Sur and the organizational climate. Also, the researchers' perspective is guided the desire to provide insights and information regarding the relationship of leadership skills of the administrators and the institutions organizational climate. A questionnaire checklist was administered to the faculty/staff respondents chosen in random. The study revealed that predictors of administrators' leadership skill were all effective. For the prevailing organizational climate, the perception of faculty and staff were based on the following predictors, namely, intimacy, engagement, hindrance and esprit while the collective perception of faculty/staff relative to the Administrator were based on the following predictors: consideration, aloofness, thrust and production emphasis. The test of correlation between the organizational climate variables of intimacy, engagement, esprit, thrust, consideration, aloofness and production emphasis posted no significant relationship to all domains of the leadership skills.
\end{abstract}

Key words: Leadership Skills, Organizational Climate, and J.H Cerilles State College

\section{INTRODUCTION AND BACKROUND}

A strong leadership is the backbone of an organization. It is the leaders vision coupled with support as well strategies, which serve as catalysts for the development of individual strengths that can propel any organization to move forward, the leaders organize time, and foster shared leadership to take advantage of individuals expertise, strengths and talents and encourage professional growth. Hence, leadership is the single most important ingredient of an organization's success, it has the power to make the system attain excellence and achieve goals. Differently stated, leadership is a multi-faceted driver of an institution to succeed (Wong, 2001). Also, Bernardo (2006) claims that in any human organization, the most fundamental resource is the people, and the most important factor that determines the fate of the organization is leadership.

Cagogo (2006) mentioned that leadership is crucial in any kind of organization or institution. It determines organizational direction and affects the whole system in organization in positive or negative way.

In recent years, leadership had been unquestionably accepted and therefore recognized a crucial component in the improvement of individual schools, colleges, and higher education institutions not only here in the Philippines but globally as well. Along with this, is the growing understanding of the positive effects of good leadership on education system as whole (Brundett \& Rhodes, 2014). Also, Sestina 2010 believed that the success and failure of the entire system depends on the leadership skills too. So, as key figures in the entire educational organization, leaders are expected to effectively coordinate efforts to meet the challenges of a fast-changing world. They are expected to effectively coordinate efforts to meet the challenges of a fast-changing world. They are to make the organization demonstrate the characteristics that reflect strength of character and the will to succeed. Goodall (2006) had noted that all outstanding performing educational institutions leaders are possessed with excellent management competence, and, of course, with outstanding research career. Also, Glaser (2005) pointed out the rationale behind why leaders could fail in their respective institution, to wit: there is no lack of collective focus, common goal, and pooled foresight; no organizational direction and unclear strategy; absence of respect to each other within the organization; mismanagement of resources such as talent, creativity and responsibility; failure to breakdown walls between division; no team spirit and no consensual agreement, rules of engagement not clear, and decision-making process; and lack of hope and spirit while organizational climate also influences the success of the organization. Many organizations, however, struggle to cultivate the IJRP 2021, 69(1), 62-72; doi:.10.47119/IJRP100691120211649 
climate they need to succeed and retain their most highly effective employee. Indeed, according to the study results it showed that profit margins were high $71 \%$ higher in organizations with emerging climates than in those with poorer climates. Likewise, sustaining good organizational relationship in a certain group creates a great place to work for both leader and members. Leaders/administrators should know then how to deal, motivates members, and create a climate in the organization which is conducive for the subordinates to work and stay. On this, higher education organizational and leadership climate is not exempt on this. For the reason that these types of institutions are supposed to be the bastion of excellence in leadership since they laid down the foundation of the nation competence and values. According to Salmi (2009), education at the tertiary level helps countries to be competitive globally through the development labor force that can compete at the global level as well as in the creation and application of ideas and technologies. This is especially true for colleges and universities enacted by law underpinned by a vision to pursue higher level of education that is geared towards national development. Such premise, poses significant challenges specifically to administrators of State-run higher education institutions wherein there is an increasing competition, and this demands exceptional leadership qualities.

The State-run Universities and Colleges are confronted with the taxing of educational reforms that included the rationalization of programs and utilization of resources, the strengthening of standards and quality, the adoption of international standards, the modernization of facilities, building-up research and development programs, and the adoption of a Unified University System (RUS) (Palencia, 2015). Leadership and organizational climate are two concepts interplaying in the organizational performance.

With the above premises, the researchers are prompted to determine the level of the leadership skills of the administrators in the Public Higher Educational Institution (PHEI) in Zamboanga del Sur. Also, the researchers' perspective is guided the desire to provide insights and information regarding the relationship of leadership skills of the administrators and the institutions organizational climate.

\section{LITERATURE REVIEW}

Leadership is crucial in any kind of organization or institution. It determines organizational direction and affects the whole system in organization in positive or negative way. (Cagogo, 2006) and Gill (2011) defined leadership as a practice wherein to influence a group of individuals in order to attain a targeted goal. This therefore connote that leadership is not a trait nor it is an attribute that resides solely in the leaders, but instead such is a transactional event which takes place between leader and followers. Further, Bass (1981) viewed relational leaders as individuals who solicit advice, opinion and information from followers and check decisions or share decision-making with followers. As supported by David and Margolis (2015) stated that seeking \& giving are crucial to be an effective leader and in the process of decision-making. These leaders use their power and influence to set constraints within which followers are encouraged to join in deciding things that needs to be done (Brophy, 2004). Whetten and Cameron provided an empirical basis for effective leadership and noted three characteristics: first, the skills are behavioral; second, it is the paradoxical; third, skills are interrelated and overlapping. Based on this, Whetten and Cameron then developed models for both personal and interpersonal leadership skills.Fig. 2 show the model of personal skills.

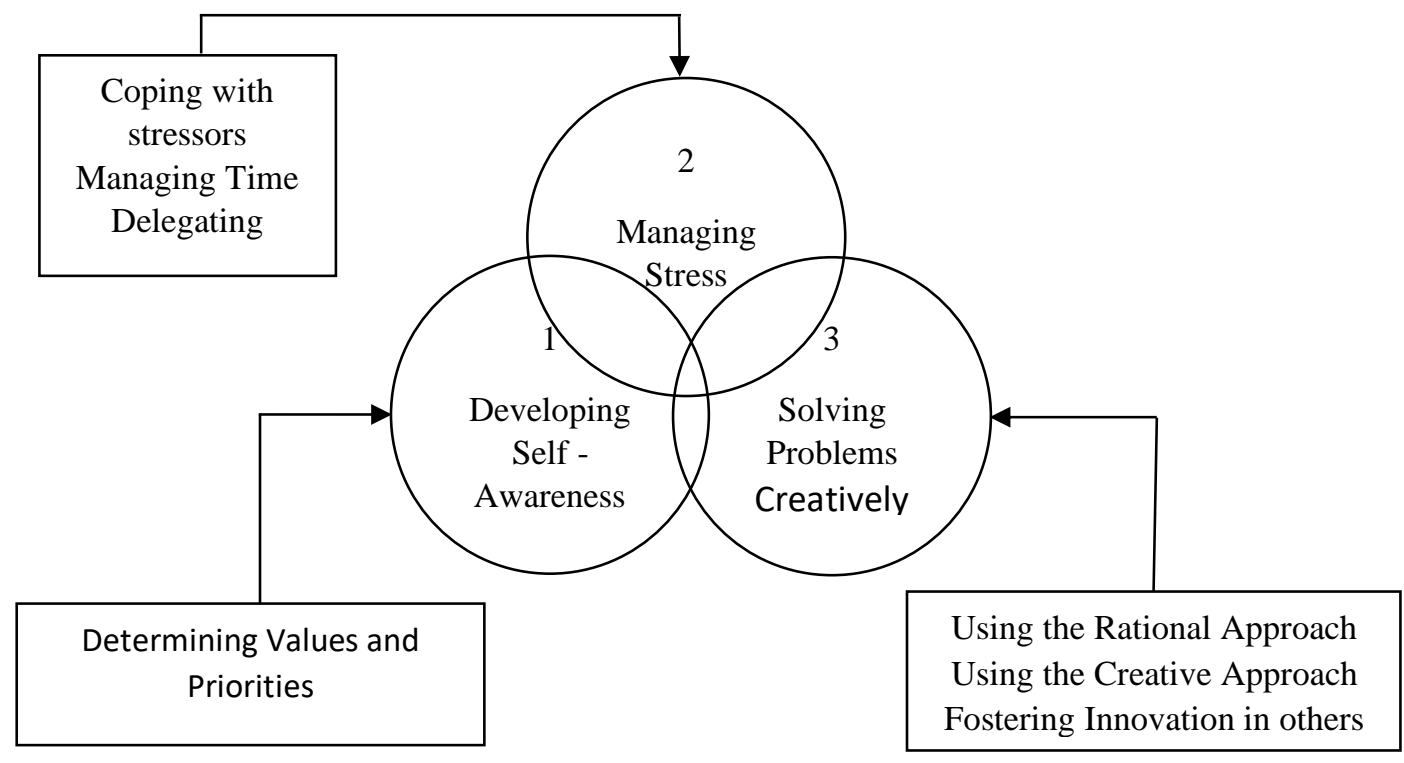

Figure 1. Whetten and Cameron's Model of Personal Skills 
They identified three aspects of personal skills namely: developing self- awareness; managing stress; and solving problems creatively. Developing self-awareness consist of determining values, priorities, identifying cognitive style, and assessing attitudes towards change. Managing stress includes coping with stressors, managing time, and delegating. Solving problems creatively can be described as using the rational approach, using the creative approach, and fostering innovations to others. These components overlap and interrelate.

Whetten and Cameron developed further the model of interpersonal skills as presented in Figure 3 which includes communicating supportively, gaining power and influence, motivating others, and managing conflicts.

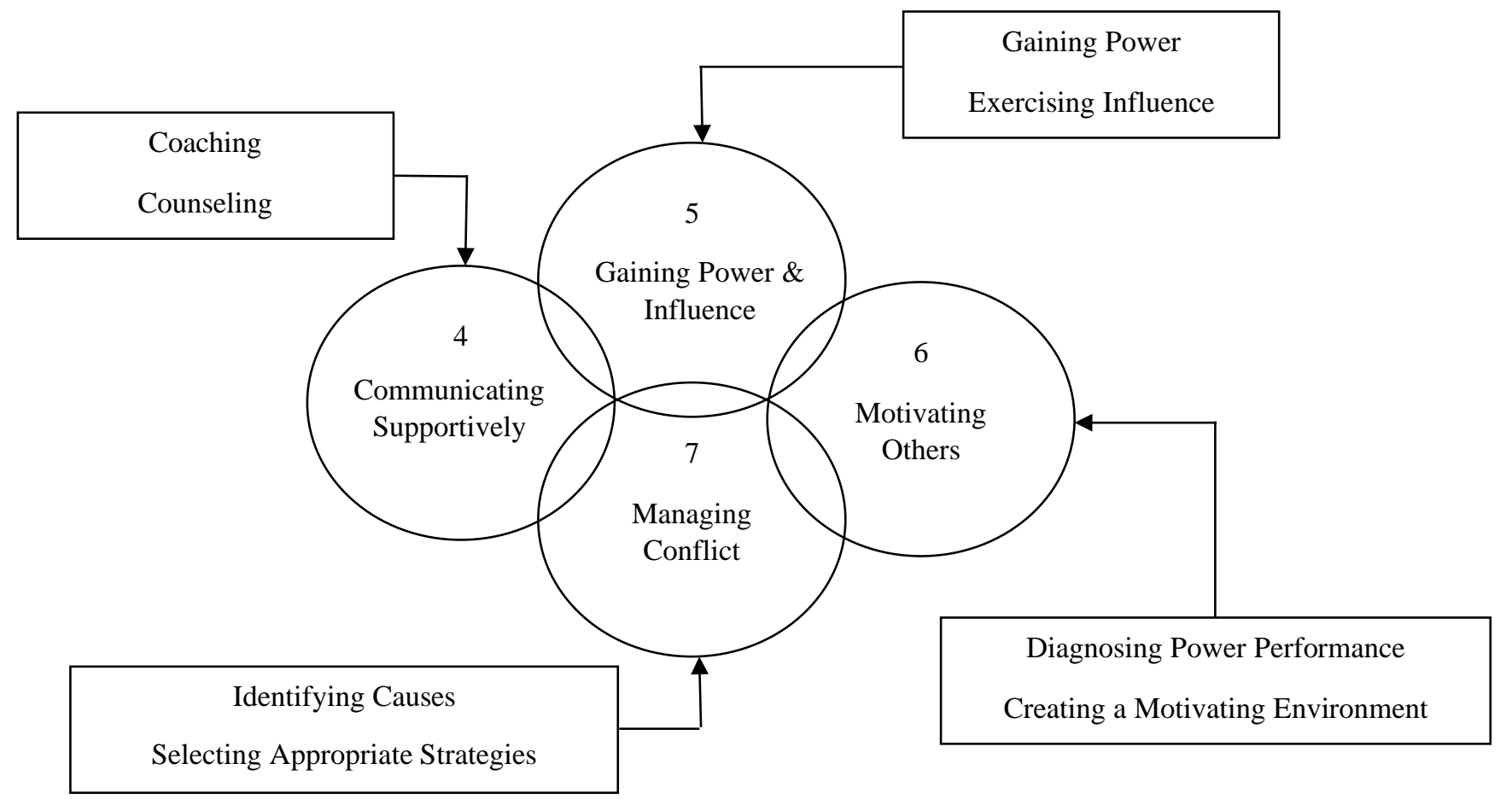

Figure 2. Whetten and Cameron's Model of Interpersonal Skills

Communicating supportively consists of coaching, counseling, and listening. Gaining power and influence is described as gaining power, exercising influence and empowering others. Diagnosing power performance, creating a motivating environment and rewarding accomplishment illustrate motivating others. Managing conflicts includes identifying causes, selecting strategies and resolving confrontations.

\section{Leadership and Motivator}

School Administrators, as leaders of the schools, play important roles in the goal-setting process geared towards the students' achievement for the improvement of the school's performance. Jones and George (2006) stressed that school administrators provide examples for teachers, make decision concerning the use of human and technical sources, and mobilizing teachers support for specific organizational goals. Thus, the school's strong collaborative efforts among the people working towards its goals through the leadership of the school administrators determine the success of the school. (Jordan, 2008). Employees performance is a function of motivation and competency. Employee's performance is a function of motivation and competency. Knowing the teachers in school and improving or maintaining their job satisfaction will make the school effective. Enhancement of self-motivation will encourage the members to work for the fulfillment of both the individual and organizational goals. Furthermore, motivation does not only influence quality and productivity but it also contributes to the work environment. With the presence of trust among the members of the organization, teamwork for a greater productivity in it is possible to happen (Stevenson, 2008). Daft (2008), supports Stevenson's idea. He stresses that those school administrators as leaders of change have something more to do in leading the members of organization.

Daft (2008), supports Stevenson's idea. He stresses that those school administrators as leaders of change have something more to do in leading the members of organization. Hill and McShane (2008) think that school administrators also take in a leadership role get things done within organizations. As leaders, they influence, motivate and direct the members and to strategize plan, control, and develop. In addition, Leith wood (2004) pointed the human dimension of leadership involves the consideration of people as individuals as well as institutional members. School leaders should acknowledge that colleagues are who have their 
own lives, wants, and needs outside the school. It is therefore important for leaders to ensure that while they are focusing on achieving institutional goals and collaborative decision-making, they do not overlook the other needs of this individual. Along with this, Maslow's view of motivation was taken into consideration in motivating people, which are based on needs. that consist of: basic physiological, safety and security needs, social affiliation or belonging needs, esteem needs, and self- actualization. The said hierarchy of needs rested on the assumption that when lower needs should first be sufficiently gratified and the successive higher-level needs would then emerge. Based on this theory, school administrators should identify the means and provision for the highest order needs of their faculty and staff, while making sure that the lower order needs are satisfied (Daft, 2008). Therefore, a leader's behavior conveys the expectations and values that sets the tone for the organization organizational climate (Holloway, 2012). As such, there are two types of leadership behaviors, that is, task-oriented behavior and relationsoriented behaviors. Task-oriented Leadership Behaviors Task-oriented leaders are focus with achieving goals. They do this by facilitating the accomplishment of goals through clear definition of roles and responsibility, establishing goals and protocols in the assessment and evaluation of achievement, direction oriented, setting timelines, and leading the way on how the goals must be achieved. Task-oriented leaders utilize a one-way communication approach. This is in order to clarify what should be done, delineation of responsibility, and how the task is to be carried out. Task-oriented leaders will do this through coordination, planning and scheduling of activities. Likewise, they provide motivation, equipment, supplies and technical assistance for completion of tasks (Northouse, 2007). Task-oriented behaviors include clarifying roles and setting of objectives, monitoring of performance and its concomitant operations, and short-term planning. Clarification of assigning tasks, job responsibilities, and setting of expectations, and monitoring of behaviors that includes but not limited to the inspection of progress and work quality. Planning includes ascertaining staffing requirements and its appropriateness in the achievement of goals and objectives while relations-oriented leaders are more concerned in the development of interpersonal relationship. It involves a communication method which can be considered two-way, which is characterize in terms of social and emotional support to coworkers and their predicaments (Northouse, 2007). Further, relations-oriented leaders would show an understanding of the problems faced by their employees. They help their employees develop their careers by emphasizing information that have bearing on their job. They allow individual autonomy in work, and they show appreciation. According to Martires and Fule (2000), the capacity of subordinates to perform can be improved through the leadership behavior of school administrators. They emphasize that the behavior of a leader tends to develop high performance and productivity of employee through the following application: good supervision, better human relations, and best policies and procedures. Thrust of early behavior leadership theory focuses on leader behavior, instead of on personality traits in handling responsibilities. It is believed that leader behavior directly affects work group effectiveness. As aptly stated by Lawler (2001), it is determined by managerial behavior that takes into account individual and environmental factors, in terms of needs, desire and goals, decision in the organization, and alternative behavior on the basis of their work expectations from the subordinates. Another important characteristic of successful managers as leaders in an organization is the values they hold and the strength of these values.

Hill and McShane (2008). Bush (2008) believed that leadership begins with the character of leaders, expressed in terms of personal values, self-aware \& emotional\& moral capability.

\section{Organizational climate}

The concept of organizational climate has generated much more research and until recently was used by most organizational theorist to capture the general feel and atmosphere of school organizational climate has tied to the process of developing measuring instruments (Hoy, 2005) climate has its historical roots in the disciplines of social psychology and industrial psychology. As stated by Owens (2004) organizational climate relates to atmospheric, personality, tone, or ethos. Halpin and Croft (1963) recognized that the foundational work in school climate is generally recognized as that of morale, but admitted that time consideration puts restriction to interaction between the administrators and teachers. Their research examined teachers disengagement from the teaching-learning process, and the extent to which administrators burdens teachers in terms of routine duties and demands, perceived personal needs of are being satisfied and are accomplish, a positive outlook relative to their work, friendly enjoyment of social relations, school administrators aloofness/ reliance to rules and policies rather than that of informal contacts to their teachers, principal closeness of supervision of teachers as a consequence of working together to move the organization in positive direction and that teachers perceived that the administrators would treats them humanely. All these factors combine together help define the climate of the school. Consequently, a great variety of instruments have been designed to measure organizational climate. The first of these was that of Halpin and Croft (1963) Organizational Climate Description Questionnaire. This 64-item climate assessment tool comprises of 8 sub-scales that relates to behavior of teacher and principal: (a) disagreement, (b) hindrance, (c) spirit, (d) intimacy, (e) aloofness, (f) production emphasis, (g)thrust, (h)consideration. After measuring the organizational climate of 71 schools, Halpin and Croft (1960) found six major climatic types: (a) open, (b) autonomous, (c) controlled, (d) familiar, (e) paternal, (f) closed. Also, as reflected in the behavior of teachers and principals, Halpin and Croft (1963) identified eight dimensions of school climate such as engagement, hindrance, esprit and intimacy and aloofness, production emphasis, thrust and consideration. They reduced these eight dimensions to six broad and more comprehensive dimensions or types of climates i.e., open, autonomous, controlled familiar, parental and closed, defining each of these with reference to the degree of presence or absence of the eight elements or dimensions of the climate. They developed a tool OCDQ (Organizational Climate Description Questionnaire) was first assumed that something actually exists which can properly be called organizational climate. Further, it was also assumed that organizational climate is associated to the behavior of teachers and principals. Organizational climate can also be best described as: Centralized and hierarchical or www.ijrp.org 
decentralized. Centralized organizations give certain individuals power over others, meanwhile decentralized organizational climates have authority spread out between different members. As workers become more specialized, they need more autonomy and self-regulation, since authority figures will not always have the knowledge necessary to manage more sophisticated tasks. However, when it comes to more responsibilities or burden of work a decentralized organization is greater compared to that of a centralized organization since it is the rank and file that mainly decides as to which actions to consider whether in formal or informal organizational structure. Formalized structures follow standard rules on how workers should carry out their activities and functions, in informal organizational structures it gives members the freehand to carry out solutions to problems, this gives the members more leeway when it comes on how to execute their roles and responsibilities.

According to Isaksen and Ekvall (2007), organizational climate is defined as the patterns of recurring behavior and feelings that defines the kind of life in an organization. Also, Organizational climate is the totality of perception that individuals have about their organization and also it serves as the global expression of what an organization is all about. It consists of separate individual perception about the internal environment in the organization and can be measured along dimensions as trust, hindrance, engagement, spirit, intimacy, aloofness, production emphasis, and consideration.

\section{METHODOLOGY AND DATA}

This investigation made use of descriptive method of research. It was conducted in the three organic Campuses of JH Cerilles State College in which the sole Public Higher Educational Institution in Zamboanga Del Sur located in the three different campuses in three location namely: Dumingag campus is located in the municipality of Dumingag which is the heartlands of Zamboanga peninsula. It is the northwest of the fertile Salug Valley and have boundaries in the north with the Municipality of Sergio Osmenia, Zamboanga Del Norte, in the East Municipality of Mahayag, the Municipality of Sominot and Midsalip in the south, and the Main Campus is situated at the municipality of San Miguel. San Miguel is situated in the center of the Baganian Peninsula., Lakewood Campus is located at the municipality of Lakewood. Lakewood is position in the eastern part of Zamboanga Peninsula; from Pagadian City it is about 42 kilometers away. The data were collected by means of a questionnaire checklist, consisting the variables of leadership skills (Based on the model of Whetten and Cameron) with four-point scale, was used to generate the responses from the respondents. Descriptive and inferential tools were used for the analysis and interpretation of data.

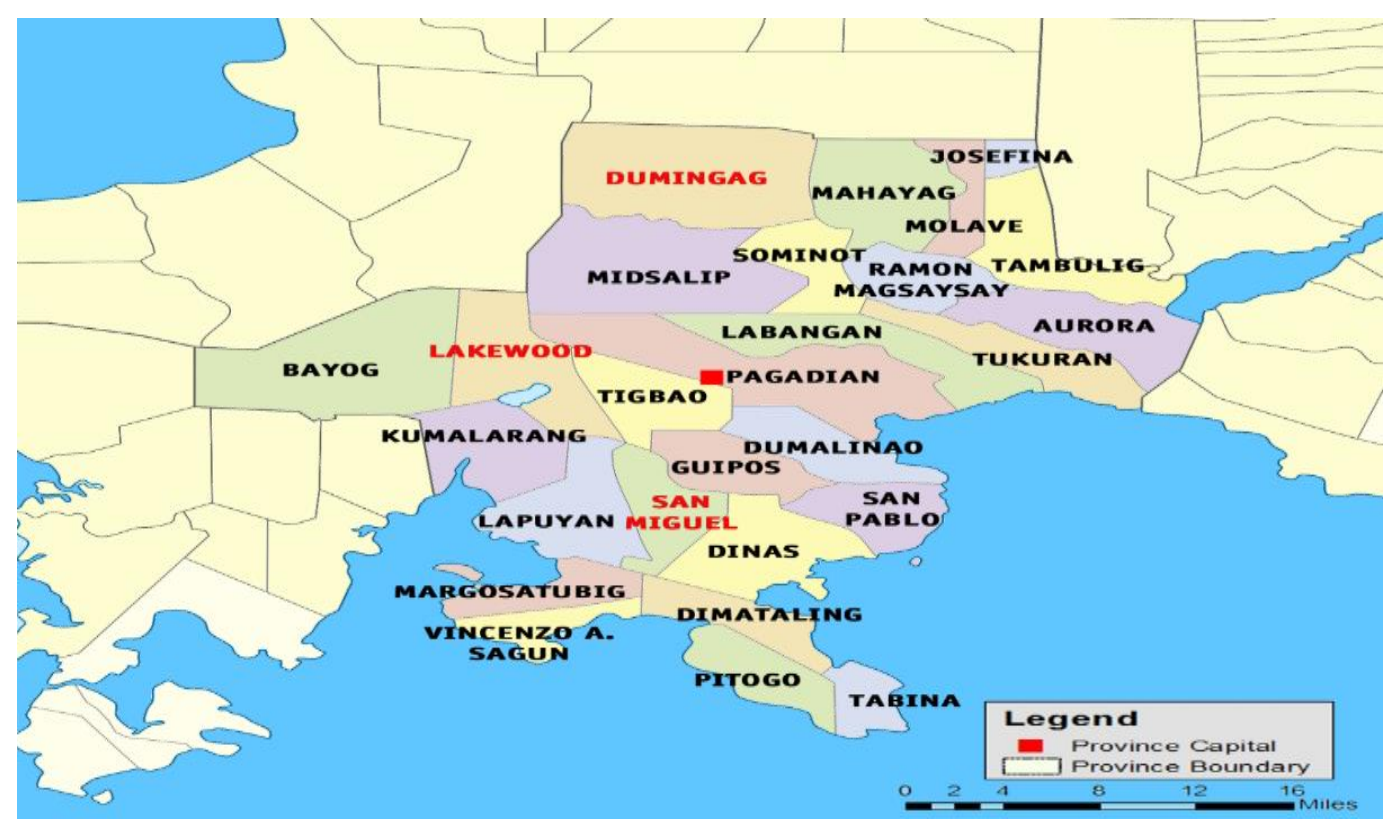

Fig.1: Map of the study site (www.google.com) 


\section{PRESENTATION AND INTERPRETATION OF RESULTS}

Table 1. Leadership Skills Employed by Administrators in PHEI, Zamboanga del Sur

\begin{tabular}{|ccccc}
\hline \multicolumn{1}{c}{ Variables } & \multicolumn{1}{c}{ Items } & Means & SD & Ranking \\
$\begin{array}{c}\text { 1. Leadership Skills Employed by } \\
\text { Administrators }\end{array}$ & 1. Developing self-awareness & 2.98 & 0.547 & 1 \\
& & & & \\
& 2. Solving problem -creatively & 2.21 & 0.574 & 6 \\
& 3. Communicating Supportively & 2.77 & 0.593 & 2 \\
4. Gaining Power and Influence & 2.5 & 0.547 & 5 \\
& 5. Motivating Others & 2.57 & 0.624 & 3 \\
& 6. Managing Conflict & 2.49 & 0.648 & 4 \\
\hline \multirow{2}{*}{ Average } & & $\mathbf{2 . 5 9}$ & $\mathbf{0 . 5 8 9}$ &
\end{tabular}

As depicted in Table 1, there were unarguably six types of leadership skills that are being employed by individuals, which previous studies have already established. These are developing self-awareness, solving problems creatively, communicating supportively, gaining power and influence, motivating others, and managing conflict. The over-all result shows that the administrator leadership skill is effective in managing their respective delivering unit. Moreover, among the predictive in the leadership skills, the developing self-awareness garnered the highest mean result of 2.98 (99.33\%), indicating that the administrator recognized the significant of understanding the concept of self-wherein awareness of one's own potential to include the weaknesses which enable the leaders/managers to work effectively. According to the study of Cornell School of Industrial \& labor relation (2010) that being aware of one's own weaknesses enables executives to level off with others who have differing strengths, thus easily able to accept someone with better ideas or abilities than their own and therefore benefit from that. Also, developing self-awareness as a leader could strengthen individual performance as well as organizational performance. Ultimately, the complete amount of understanding and wisdom that self-aware leaders possess can equipped them with critical skills for success. Boyatzis and McKee (2005) theorize that ineffective leadership is due to lack of self-awareness, rather than general inability. They hypothesized that emotional skills are needed to address complex situations are tapped into less often by leaders who possess lower self-awareness (Boyatzis \& McKee, 2005). Research had found out that the more we see ourselves clearly, the more confident and more creative we become, and the sounder decisions we make, and the stronger relationships and therefore communicate more effectively (Eurich,2018). Thus, developing self-awareness as a leader strengthens individual performance as well as organizational performance, and the amount of understanding, trustworthiness and wisdom that self-aware leaders have endowed them with skills for achievement (Gallo,2019). Palmer (2014) believes this process requires a self-focused and self-reflected mind-set, which may lead to self-discovery. Further, the significance of self-awareness goes beyond well-being and mental health for it may include substantial impacts on roles and responsibilities for an efficient functioning of work. Its important effects are on performance, and along with reflection and mindfulness it encourages persistence with tasks despite performance-related stress (Feldman, Dunn, Stemke, Bell, \& Greeson, 2014) and rumination related to interpersonal difficulties (Brinker, Chin, \& Wilkinson, 2014). 
Table 2. Organizational Climate Among Faculty and Staff in PHEI, Zamboanga del Sur, In Terms as a Group

$\begin{array}{ccccc}\text { Variable } & \text { Items } & \text { Mean } & \text { SD } & \text { Ranking } \\ & \text { Intimacy } & 2.98 & 0.65 & 1 \\ \text { 2. Organizational Climate (the faculty/staff perception as a } & \text { Engagement } & 2.9 & 0.644 & 2 \\ \text { group) } & \text { Esprit } & 1.13 & 0.701 & 0.713 \\ & \text { Hindrance } & 2.82 & 4 \\ \text { Average } & & \mathbf{2 . 4 6} & \mathbf{0 . 6 7 7}\end{array}$

The faculty and staff of JH Cerilles State College System perceived as to what they regard as the prevailing organizational climate, intimacy holds the highest rank among the other predictive which garnered a mean of 2.98(99.33\%), posted as agree. The results established that the faculty/staff are conscious on the significant of intimacy among individual within the group. Faculty/ staff tend to be highly engaged with their colleagues and tend to work well with each other. They established a sensitive and intimate environment to work with. Sullivan declares that intimate relations, is a relation that individuals as getting sensitive about each other's issues and they help each other. also includes, sympathy and understanding, number of interaction and the mutual activities (Stephen, et.al.,2011). In such relation, people tend to assist each other in order to make them happy and establishing a personal value for them and they are not working for a benefit or they are not following a specific goal for helping (Loveresia, et.al, 2014). Likewise, intimate relations increase within workplace increase necessities of knowledge share among employees, job commitment, cheer and happiness within workplace; this issue also can strength organizational climate (Kroos, et.al, 2006). Also, Laurenceau, et.al (2004) pointed out that intimacy is personal, with a subjective sense of connectedness that is an outcome of an interpersonal, transactional process that consist of self-disclosure and the others responsiveness. Hence, intimacy implies sharing of what is inmost to others. According to Popovic (2005) this involves seeing and being seen, which is possible through empathic perception and a depth of understanding of the other. Intimacy consists of positive behavior, which may not be merely ideational but also have an outward manifestation, and with a communication style wherein both individuals experience a sense of shared meaning (Firestone \& Firestone, 2014). In the context of leadership, once a leader establishes a certain level of intimacy with an employee, the employee begins to trust that leader and feel safe and comfortable enough to deal honestly and openly with him or her. Once intimacy is established, people are more open to feedback, which gives leaders the leverage to provide both redirecting and reinforcing feedback. (Align4Profit, Inc. 2013).In a Towers Watson 2010 Global Workforce Study of 20,000 employees in 22 markets, their findings indicate, the current climate of uncertainty and constant change indicates that employees increasingly value leaders who connect with the workforce on an emotional level. In the same study they observe, that aspiring for more emotionally intelligent aspects of leadership can make employees feel disconnected from their organization and consequently they would be looking for leaders that exude with integrity and empathy, and with a focus on employees' development. In other words, people respond well when leaders recognize the unique value they bring. In addition, Leadership Intimacy begins and demands an acute awareness of self, an in-depth self-knowledge, and excellence in self-regulation. (Align4Profit, Inc. 2013). 
Table 3. Organizational Climate Among Faculty and Staff in the PHEI (The collective perception of faculty/staff concerning Administrators)

\begin{tabular}{clcccc} 
Variable & \multicolumn{1}{c}{ Items } & Mean & SD & Ranking \\
& 1. Thrust & 2.74 & 0.608 & 3 \\
$\begin{array}{c}\text { 1. Organizational Climate (The collective perception } \\
\text { of faculty/staff concerning the Administrator) }\end{array}$ & 2. Consideration & 2.87 & 0.646 & 1 \\
& 3. Aloofness & 2.85 & 0.763 & 2 \\
Average & 4 Production Emphasis & 2.73 & 0.714 & 4
\end{tabular}

After having presented as to the degree of agreement as to what particular organizational climates currently dominated among faculty and staff in the PHEI in terms as group, this therefore set the ground wherein to ascertain as to the currently dominant organizational climate as perceived by faculty/staff concerning to the administrator. Thus, at this point, we would now try to look at the findings relative to the currently dominant organizational climate among administrators. By being able to present this particular finding, thus, it could provide further insight relative to the organizational climate from the perspective of the administrators. As revealed in Table 3, based on the indicators of each organizational climate given to faculty and staff on how they perceived their administrator, they then identified consideration as the highest among the four predictors with a mean of $2.87(95.6 \%)$ as their administrator carrying out their roles and responsibilities as compared to aloofness; thrust, and production emphasis. As observed in the table presented that the mean in all of the predictive have a slight difference in the result and also having the same qualitative description as agree. Along with this, the results implied that the faculty/ staff viewed their administrator to have a behavior that is easy and authentic, able to lead, direct and control not aloof or distant, shows compassion and concern, knows to follow rules and regulations with minimum hindrances to faculty and staff and also maintains definite standards of performances. Research had found out that consideration correlates more strongly with feeling of satisfaction of subordinates. Both Bass (1990) and Yukl (1998) noted that consideration correlates with satisfaction. Considerate leaders are empathic (Fleishman \& Salter, 1963). (Piccolo \& Moise, 2019) Therefore, considerate leadership is particularly characterized by a leader behavior that underscore commitment towards the development of personal relationships with followers, concern for others, willingness to understand others unique preferences and work styles with subordinates, and facilitative in terms of team work. 
Table 4. Pearson correlation between Organizational climate and Leadership Skills

\begin{tabular}{cccccc} 
Variables & \multicolumn{9}{c}{ Leadership Skills } \\
Organizational & $\begin{array}{c}\text { Developing } \\
\text { Climate }\end{array}$ & $\begin{array}{c}\text { Solving } \\
\text { Problems } \\
\text { creatively }\end{array}$ & $\begin{array}{c}\text { Communicating } \\
\text { Supportively }\end{array}$ & $\begin{array}{c}\text { Motivating } \\
\text { Others }\end{array}$ & $\begin{array}{c}\text { Managing } \\
\text { Conflict }\end{array}$ \\
\hline Intimacy & -0.149 & -0.055 & -0.104 & -0.082 & -0.105 \\
Engagement & 0.0007 & 0.099 & -0.027 & -0.047 & 0.049 \\
Esprit & -0.068 & -0.013 & -0.114 & -0.056 & 0.004 \\
Hindrance & 0.068 & 0.074 & -0.023 & -0.043 & 0.067 \\
Thrust & -0.019 & 0.026 & -0.032 & 0.009 & 0.025 \\
Consideration & 0.005 & 0.043 & -0.033 & 0.018 & 0.053 \\
Aloofness & 0.025 & 0.065 & -0.042 & 0.024 & 0.006 \\
Production emphasis & 0.008 & 0.092 & 0.015 & 0.03 & 0.008 \\
\hline
\end{tabular}

**. Correlation is significant at the 0.01 level (2-tailed). *. Correlation is significant at the 0.05 level (2-tailed). $r$ is interpreted using Cohen's Scale: -0.3 to $+0.3=$ Weak Correlation, -0.5 to -0.3 or +0.3 to $+0.5=$ Moderate Correlation, -0.9 to -0.5 or +0.5 to $+0.9=$ Strong Correlation, -1.0 to -0.9 or +0.9 to +1.0

= Very Strong Correlation

Table 4 presents the correlation between leadership skills and organizational variables. The organizational climate variables of intimacy, engagement, esprit, thrust, consideration, aloofness and production emphasis posted no significant relationship to all domains of the leadership skills.

\section{CONCLUSION AND RECOMMENDATION}

The leadership skills employed by the administrators in the Public Higher Educational Institution in Zamboanga del Sur, comprising the following predictors in terms of self-awareness development, communicating supportively, motivating others, conflict management, advancement of power and influence and solving creatively were all effective. This is a good indication that administrators provide a major impact to the institution. They established contact with their equals, deal with their subordinates and guide them, mediate in conflicts and resolve issues by weighing various alternatives.

The practice of good leadership entails growth in the institution. with this premise, the administrators need to come-up an intervention on the creative problem-solving skill. This skill gives a mechanism in the identification of things, in figuring out why they are broken and in making of a course of action in order to fix them. Moreover, the institution should integrate the capacity development or capacity building in the crafting of a plan for human resource development. This may enhance the creative problem-solving skill of the administrator. Providing the appropriate training and seminar may a great support to the administrator/s to understand more on their role in the attainment of the institutions Vision, Mission and Goals. For the organizational climate, it is important to create a conducive environment involving good relationships with administrators to contribute to the organizational commitment of the faculty/staff and improve their perception of organizational performance. Also, adopting work teams can improve the work environment by constituting a warm and cooperating atmosphere while reducing the conflict. 


\section{REFERENCES}

Bernardo, B.A (2006). Management of colleges and universities of science and technology. Laguna: UPLB Foundation, Inc. and SEARCA

Bratton, V. K., Dodd, N. G., \& Brown, F. W. (2011). The impact of emotional intelligence on accuracy of self-awareness and leadership performance. Leadership \& Organization Development Journal.

Brinker, J. K., Chin, Z. H., \& Wilkinson, R. (2014). Ruminative thinking style and the MMPI-2-RF. Personality and Individual

Differences, 66, 102-105. doi: 10.1016/j.paid.2014.03.001

Brundett. C.\& Rhodes C., Researching Educational Leadership \& Management: Methods \& Approaches. SAGE Publishing Inc.

Boyatzis, R. E., \& McKee, A. (2005). Resonant leadership. Boston, MA: Harvard

Business School.

Bush T. (2008). Leadership \& Management Development in Education, London: SAGE. School of Management task force (SMTF)

Cagoco, Eugene. (2006). Perceived Leadership Style of Administrators' of Sacred Heart High School. An Action Research. De la Salle University-Manila.

Daft, Richard L (2008). Management. $9^{\text {th }}$ Edition, South Western: Thomson Learning Area

David A. Garvin \& Joshua D. Margolis. The Art of Giving and Receiving Advice. Harvard Business Review.2015

Feldman, G., Dunn, E., Stemke, C., Bell, K., \& Greeson, J. (2014). Mindfulness and rumination as predictors of persistence with a distress tolerance task. Personality and Individual Differences, 56, 154-158.doi: 10.1016/j.paid.2013.08.040

Firestone, R.W., \& Firestone, L. (2004). Methods for overcoming the fear of intimacy. In D.J. Mashek, \& A. Aron (Eds.), " $e$ handbook of closeness and intimacy (pp. 375 - 396). Mahwah, NJ: Erlbaum.

Fleishman, E. A., \& Salter, J. A. (1963). Relationship between the leader's behavior and his empathy toward subordinates. Journal of Industrial Psychology, 1, 79-84

Gallo, Sarah (2019). Importance of self-awareness in leadership

Glaser, J.E (2005). Creating we: Creating I-thinking to we-thinking. Avon Massachusetts: Platinum Press

Goodall, A.H, (2006). Should research universities be led by top researchers, and are they? Journal of Documentation, 62 (3):388-411.

Gil, R (2011). Theory \& Practices of Leadership

Halpin, A. W\& Croft, D. D (1962). The Organizational Climate of Schools. Chicago

Hill, Charles W.L \& Stevenson Mc Shane (2008). Principles of Management. International Edition, Boston. Mc GrawHill

Holloway, J.B (2012). Emerging Leadership Journeys, Vol.5155. Regent University School of Global Leadership \& Entrepreneurship. ISSN 1941-4684/editorial @ regent.edu

Hoy, W. K \& Miskel, C.G. (2005), Educational Administration ( $3^{\text {rd }}$ Edition). USA

Http: www.pjbourbeau.com/main.cfm?p=401\&1=en

Http://www.ehow.co.uk/info 8543259 elements-organizational-climate.html

Https//ezinearticles.com/?Importance-of-Communication-in-an-Organizationsid=423299

Isaksen, S.G. \& Ekvall, G. (2007). Assessing the context for change: A technical manual for the situational outlook questionnaire. Orchard Park, N.Y: The creative solving group

Jones, Gareth R.\& Jennifer m. George (2006). Contemporary Management. $4^{\text {th }}$ Edition. Boston: Mc Graw- Hilll ijrp.org 
Jordan, Pablo Jr. School leadership in lasso secondary schools. Towards a model of school leadership. Basis for Supervisory Program. Dissertation, LDCU

Lawler, P. \& King, K.P (2000). Effective Principles of Faculty Development

Leitwood, K. et.al. (2004). How Leadership Influence Student Learning (learning from leadership project executive summary). New York: The Wallance Foundation

Martirez, Conception \& Galileo S. Fule. Management of Behavior in Organization, $2^{\text {nd }}$ Edition, Mandaluyong, National Bookstore

Northhouse, P.G (2007). Leadership Theory \& Practices. $3^{\text {rd }}$ Edition. Thousand Oaks CA: Sage Publications

OPIF Reference Guide-DBM,2011

Owens, R.G (2001). Organizational Behavior in Education. Instructional leadership

School reform, 7th Edition. USA

Palmer, J. Q. (2014). A quasi-experimental study of changes in self-awareness and authentic leadership after participation in a volunteer event.

Palencia, R. (2015). Culture and leadership of State, Universities and Colleges (SUC's) in the Eastern Visayas, Philippines.

Popovic, M. (2005). Intimacy and its relevance in human functioning. Sexual and Relationship "therapy, 20,31 - 49.

Salmi, J. (2009). The challenges of establishing world-class universities. Washington DC: the world bank

Stevenson, William J. (2008). Operations Management. $9^{\text {th }}$ edition. New York. Mc Graw Hill 